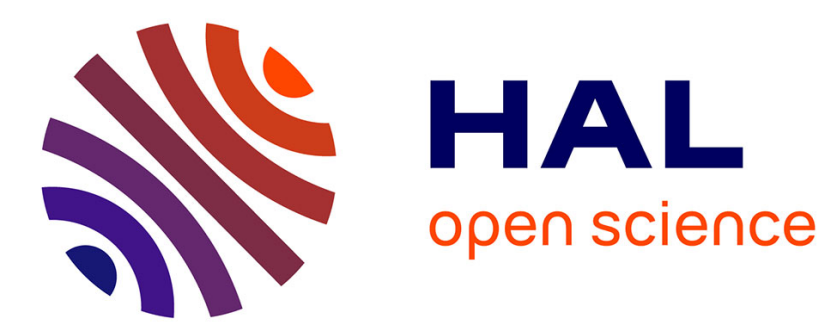

\title{
Experimental investigation of the dynamic fracture of a class of RT-PMMAs under impact loading
}

\author{
Norazrina Mat Jali, Patrice Longère
}

\section{To cite this version:}

Norazrina Mat Jali, Patrice Longère. Experimental investigation of the dynamic fracture of a class of RT-PMMAs under impact loading. International Journal of Fracture, 2020, pp.219-237. 10.1007/s10704-020-00475-x . hal-02915780

\section{HAL Id: hal-02915780 \\ https://hal.science/hal-02915780}

Submitted on 1 Dec 2020

HAL is a multi-disciplinary open access archive for the deposit and dissemination of scientific research documents, whether they are published or not. The documents may come from teaching and research institutions in France or abroad, or from public or private research centers.
L'archive ouverte pluridisciplinaire HAL, est destinée au dépôt et à la diffusion de documents scientifiques de niveau recherche, publiés ou non, émanant des établissements d'enseignement et de recherche français ou étrangers, des laboratoires publics ou privés. 


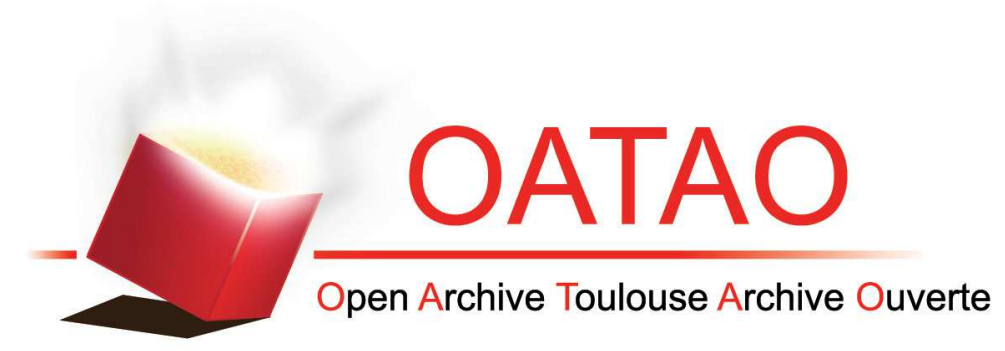

\section{Open Archive Toulouse Archive Ouverte (OATAO)}

OATAO is an open access repository that collects the work of some Toulouse researchers and makes it freely available over the web where possible.

This is an author's version published in: https://oatao.univ-toulouse.fr/26919

Official URL: https://doi.org/10.1007/s10704-020-00475-x

\section{To cite this version :}

Jali, Norazrina Mat and Longère, Patrice Experimental investigation of the dynamic fracture of a class of RT-PMMAs under impact loading. (2020) International Journal of Fracture. 219-237. ISSN 0376-9429

Any correspondence concerning this service should be sent to the repository administrator: tech-oatao@listes-diff.inp-toulouse.fr 


\title{
Experimental investigation of the dynamic fracture of a class of RT-PMMAs under impact loading
}

\author{
Norazrina Mat Jali • Patrice Longere $₫$
}

\begin{abstract}
The present work aims to investigate experimentally the crack arrest capability and dynamic fracture mechanisms under impact loading of three commercial, rubber-toughened (RT) PMMA grades differing by their rubber nano-particle concentration and resulting Charpy impact toughness. For that purpose, Kalthoff and Winkler (KW)-like impact tests were performed using gas launcher considering impact velocities ranging between 20 and $100 \mathrm{~m} / \mathrm{s}$. A high-speed camera was used to record the projectile/specimen interaction and the progressive failure of the specimen. The fracture surfaces of the fragments were observed using a scanning electron microscope (SEM). It is seen that the higher the impact velocity the larger the number of fragments. On the other hand, it is shown that increasing the rubber nano-particle concentration favors the crack arrest capability under impact loading by promoting inelastic deformation, reducing the crack propagation velocity, limiting crack multi-branching, and reducing the number of fragments.
\end{abstract}

Keywords RT-PMMA · Crack arrest · Impact loading

N. M. Jali · P. Longere $(\bowtie)$

Université de Toulouse, ISAE-SUPAERO, ICA (CNRS

5312), 31400 Toulouse, France

e-mail: patrice.longere@isae.fr

N. M. Jali

Faculty of Engineering, National Defence University

of Malaysia, 57000 Kuala Lumpur, Malaysia

\section{Introduction}

In the transportation sector in general and in the aeronautical one in particular, the engineering materials have to meet the most demanding requirements in terms of weather-resistance, protection against UV radiation and toughness in nominal service, and in terms of crash-, collision- and impact-resistance during accidental overloads. In parallel, they have to be as light as possible in a view of reducing the $\mathrm{CO}_{2}$ emissionsinduced environmental impact. In this context, we are interested here in transparent engineering materials as glass surrogate candidates.

Due to its transparency, shatter-, scratch- and weatherresistance and favorable processing conditions, PMMA is widely used as a substitute for inorganic glass. This accordingly makes PMMA a suitable material for windows protecting against bullet and blast (Hsieh et al. 2004). PMMA has thus been widely used in military aviation since World War II to replace the glass for airplane windows. It also can replace the usage of glass for windshield and armour protection. PMMA has accordingly been applied in cockpits, portholes, windshields, exterior lighting and helicopter windscreens, see e.g. $\mathrm{Hu}$ et al. (2016). This substitution helps increase the value in terms of safety because it proves to be a much safer material in battle situations for aviators (Gilbert et al. 1995).

The application of PMMA as structural material in various industrial sectors requires a good knowledge 
of its behavior and response in a wide range of loading and environmental conditions (Brown et al. 2014), in particular those involving potential damage and fracture. In this context, crack arrest mechanisms which prevent catastrophic failure in polymers are demanded in some design approaches (Kobayashi 1979) leading to many studies devoted to investigate the crack propagation in PMMA for decades (Smirnov and Sudenkov 2013). Indeed, fracture of PMMA results from complex mechanisms involving micro-voiding, micro-cracking and crazing, see (Awaja et al. 2016). In addition, the behavior and fracture of glassy polymers in general, and of PMMA in particular, is known to be strongly dependent on temperature, strain rate and loading path, see (Abdel-wahab et al. 2017; Jancar et al. 2015; Arruda et al. 1995; Chou et al. 1973; Farrokh and Khan 2010; Nasraoui et al. 2012).

A significant improvement of the low impact toughness of PMMA can be achieved by addition of several kinds of small sized fillers, see (Todo et al. 1999; Porfyrakis et al. 2002; Pearson and Yee 1991; Ognedal 2012), making it competitive with respect to other highstrength engineering glassy polymers such as polycarbonate (Lalande 2007). The two common types of fillers used for toughness increase are rubber and minerals (Ognedal 2012). Many generations of PMMA were accordingly reinforced by incorporating rubber nano-particles which yield rubber-toughened PMMA, shortly named as RT-PMMA. This toughening mechanism is mainly governed by interfacial adhesion and rubber particle size, volume fraction and morphology (Chung et al. 2001). The presence of rubber nanoparticles in the PMMA matrix is also shown to increase the inelastic deformation energy of the resulting composite material, see (Mbarek et al. 2018).

In the context of the evaluation of the residual resistance of pre-cracked structures when submitted to high strain rate reloading, the aim of the present study is to investigate experimentally the crack arrest capability and dynamic fracture mechanisms of three grades, differing from each other by their value of Charpy impact toughness, of a class of commercial shock-resistant RTPMMA under impact loading. To that purpose, Kalthoff and Winkler (KW)-type impact tests, see (Kalthoff and Winkler 1987; Roux et al. 2015), were carried out using a gas launcher. The test consists of the impact of the edge of a double notched plate made of the material at stake and investigating the conditions for crack initiation and propagation. For ductile materi- als, the crack initiated from the notch tip propagates in a direction quasi collinear to the notch axis (before slightly bifurcating), see (Ravi-Chandar et al. 2000), whereas for brittle materials the crack propagates along a direction which makes an angle close to $70^{\circ}$ with respect to the notch axis, see (Kalthoff and Winkler 1987). KW impact tests accordingly allow for identifying the ductile vs. brittle feature of material failure under high strain rate and impact loading. In the present work, impact speeds ranging between 20 and $100 \mathrm{~m} / \mathrm{s}$ were applied and frames of the progressive failure of the plates were monitored using a high-speed camera. The fractured surfaces were observed using optical and scanning electron (SEM) microscopy in view of determining the failure mechanisms.

In addition to bringing new highlights in the investigation and comprehension of rubber nano-particle reinforced PMMA fracture under impact conditions, the work presented is expected to provide with experimental data researchers and engineers elaborating or using constitutive models and conducting numerical simulations in view of discriminating approaches.

The materials under consideration are presented in Sect. 2. The impact test experimental set-up and instrumentation devices are detailed in Sect. 3. The experimental results in terms of real-time observation of the plate failure and measures of crack propagation speeds are given and analyzed in Sect. 4. Concluding remarks are finally drawn in Sect. 5.

\section{Materials under consideration}

The Polymethylmethacrylate (PMMA) is a synthetic polymer from the methyl methacrylate monomer. It is also known as acrylic, acrylic glass, plexiglass, or acrylate. It is a synthetic resin with a chemical formula of $\left(\mathrm{C}_{5} \mathrm{O}_{2} \mathrm{H}_{8}\right)$-n which is produced from the polymerization of methyl methacrylate. PMMA possesses advantages over glass in many aspects including its processability and ability to prevent optical distortions. In addition to its long-term mechanical properties, it has excellent optical properties and good resistance against chemical, heat, weather and temperature fluctuations, see (Lalande 2007).

In the present work, a class of highly transparent, glassy, shock resistant RT-PMMAs, viz. Plexiglass Resist ${ }^{\circledR}$, provided in the form of extruded plates, was considered. Impact-modified Plexiglass Resist ${ }^{\circledR}$ 
Table 1 Properties of the RT-PMMA under consideration (as given by the manufacturer)

\begin{tabular}{llll}
\hline & RT-PMMA45 & RT-PMMA65 & RT-PMMA100 \\
\hline Impact Resistance (Charpy notched impact strength- ISO 179/1eA) & At least $1.5 \mathrm{~kJ} / \mathrm{m}^{2}$ & At least 3.0 kJ/m² & At least 4.5 kJ/m² \\
Modulus of Elasticity, Et (Tensile test according ISO 527-2/1B/50) & At least 2600 MPa & At least 2100 MPa & At least 1700 MPa \\
Strength & At least $55 \mathrm{MPa}$ & At least $45 \mathrm{MPa}$ & At least $35 \mathrm{MPa}$ \\
\hline
\end{tabular}

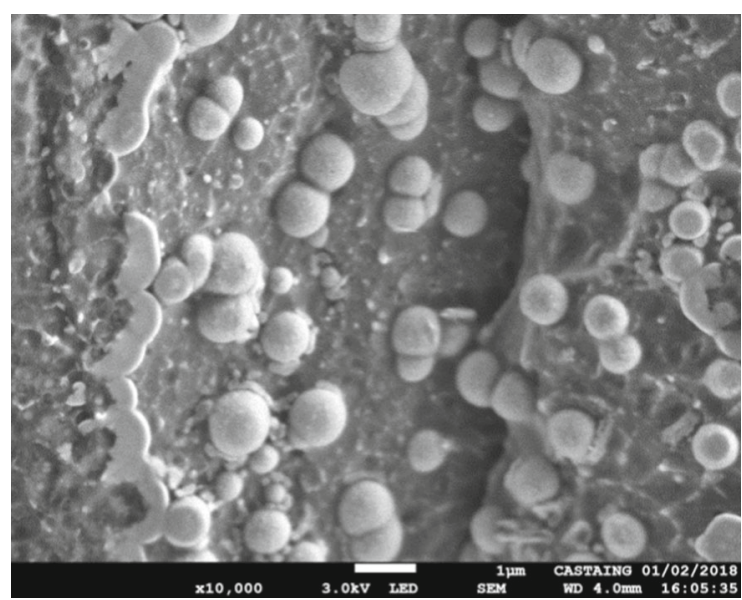

Fig. 1 SEM picture of RT-PMMA65 after liquid nitrogen fracture

have low tendency to yellowing under thermal stress, improved durable and optical properties under the action of water as well as improved weather properties, see (Patent No : EP0776931). Three different grades were taken into consideration, namely RT-PMMA45, RT-PMMA65 and RT-PMMA100. The grades differ from each other by their rubber nano-particle concentration and resulting value of Charpy impact toughness, see Table 1. RT-PMMA45 has the lowest Charpy impact toughness and RT-PMMA100 the highest one, RT-PMMA65 being in-between. According to Table 1, the higher the Charpy impact toughness is, the lower the strength is, and conversely.

A SEM picture of RT-PMMA65 after liquid nitrogen fracture is shown in Fig. 1. Figure 1 evidences the spherical rubber nano-particles and the surrounding PMMA matrix.

The rubber nano-particle concentration corresponding to a given grade is not given by the manufacturer. Particles and matrix having the same refractive index, the attempts made in this work to estimate the nanoparticle concentration from SEM pictures failed. It was then decided to proceed with a data collection from

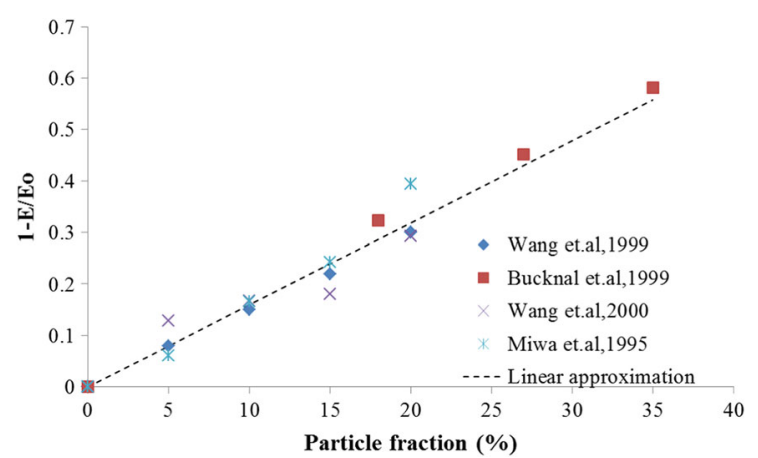

Fig. 2 Relative Young's modulus dependence on rubber particle in some RT-polymers, according to (Bucknall et al. 1984; Wang et al. 2000; Miwa et al. 1995; Wang and Lee 1999)

the literature review showing the dependence of the Young's modulus on the particle concentration in RTpolymers. The literature review does not pretend to be exhaustive. Relative Young's modulus-particle fraction curves in Fig. 2 are extracted from the works (Bucknall et al. 1984; Wang et al. 2000; Miwa et al. 1995; Wang and Lee 1999). Although the matrix and the copolymer are not necessary the same in all the studies, Fig. 2 evidences a similar linear dependence of the relative Young's modulus on the particle concentration within the particle concentration range [0-35\%]. The Young's modulus for each grade of the RT-PMMAs under consideration in the present work were obtained from tension tests, see true stress-true strain curves in Fig. 3 and specimens after the tests in Fig. 4. From the average linear regression of the curves in Fig. 2, the assumption of a value of $3300 \mathrm{MPa}$ for the Young's modulus of the plain PMMA, and the measured Young's moduli $E$ for the three grades, a coarse estimate of the nano-particle concentration $f$ for each grade can be obtained:

$$
\begin{aligned}
& f(\%)=62.79-0.019 \times E(\mathrm{MPa}) \text { or equivalently } E(\mathrm{MPa}) \\
& \quad=3300-52.556 \mathrm{x} f(\%)
\end{aligned}
$$

In Table 2 are reported the Young's moduli and nano-particle concentration estimates for the three RTPMMA grades. As explained above, these estimates are 


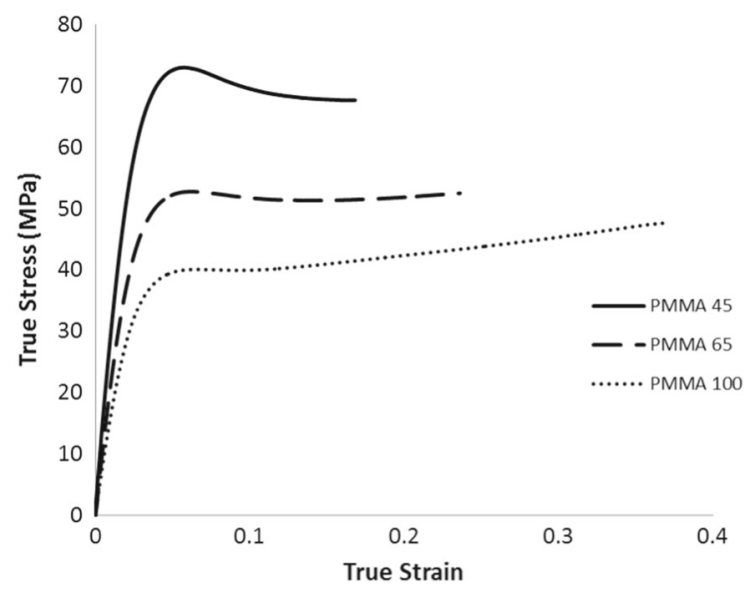

Fig. 3 Stress-strain curves for the 3 RT-PMMA grades. $\mathrm{T}=$ $298 \mathrm{~K}^{\circ} \mathrm{C}, \dot{\varepsilon}=10^{-3} \mathrm{~s}^{-1}$
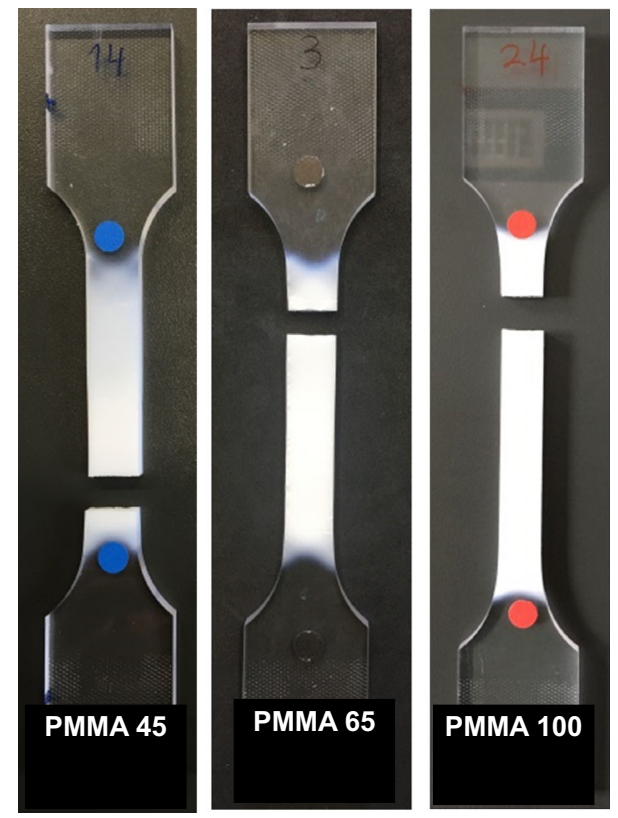

Fig. 4 Post-mortem specimens after tension loading

coarse, so in the following the grades are designated by their grade numbers.

According to Fig. 3, under the experimental conditions, the grades all exhibit a quasi linear elastic response followed by a blunt peak and then a more or less nonlinear inelastic response until fracture. The Young's modulus is close to $2684 \mathrm{MPa}$ for RTPMMA45, $2100 \mathrm{MPa}$ for RT-PMMA65 and $1400 \mathrm{MPa}$ for RT-PMMA100, i.e. higher for lower grade number, to be compared with the values reported in Table 1 . The maximum value of the strength at the peak is close to $73 \mathrm{MPa}$ for RT-PMMA45, 53 MPa for RT-PMMA65 and $40 \mathrm{MPa}$ for RT-PMMA100, i.e. higher for lower grade numbers, or equivalently lower for higher grade numbers, to be compared with the values reported in Table 1. After the peak, RT-PMMA45 evidences strain softening with a trend to saturation, RT-PMMA65 perfect plasticity and RT-PMMA100 linear strain hardening. The value of strain at fracture is close to 0.17 for RT-PMMA45, 0.25 for RT-PMMA65 and 0.37 for RT-PMMA100, i.e. higher for higher grade numbers. As a consequence, the higher the grade number and equivalently the higher the nano-particle concentration the lower its resistance and the higher its ductility, as expected.

Fractured specimens in Fig. 4 evidence more or less extensive and intense, opaque white areas. The whitening of some (semi) transparent plastics under tension loading, known as stress whitening, is generally attributed to micro-voiding and/or micro-cracking. Indeed, the formation of internal surfaces leads to local micro-heterogeneities of the refractive index which causes scattering of transmitted light in arbitrary conditions (Jerjen et al. 2013). Micro-void clusters of dimension equal to or greater than the light wavelength are assumed to be the primary cause of stress whitening, which is known as Fresnel effect (Ognedal 2012), and are macroscopically visible as white spots. Tension loading which involves positive mean stress and positive stress triaxiality ratio favors nano-particle/matrix debonding-induced micro-voiding and hence favors the formation of white areas-whereas compression loading which involves negative mean stress and negative stress triaxiality ratio does the opposite. Correspondingly, the formation of white areas evidences nanoparticle/matrix debonding-induced micro-voiding and zones of tension loading (where the stress state exceeds the interfacial adhesion resistance). Later this feature will help analyze the frames of the fragmentation of impacted plates.

This is precisely this mechanism of nano-particle/ matrix debonding-induced micro-voiding that is assumed to explain the toughening effect of rubber and mineral particles reinforced polymers. The toughening effect is reported for both semi-crytalline and amorphous polymers, and even epoxies, containing any kind of voids. The voids can be present in form of preexisting voids, self cavitating rubber particles or debonding stiff mineral particles. Moreover, the processes of debonding 
Table 2 Young's moduli and particle fraction estimates for the RT-PMMAs under consideration

\begin{tabular}{lccc}
\hline & RT-PMMA45 & RT-PMMA65 & RT-PMMA100 \\
\hline $\begin{array}{l}\text { Young's modu- } \\
\text { lus (MPa) }\end{array}$ & 2684 & 2100 & 1400 \\
$\begin{array}{l}\text { Particle fraction } \\
(\%) \text { Coarse esti- }\end{array}$ & 12 & 23 & 36 \\
mate & & \\
\hline
\end{tabular}

and void growth promote dissipation of energy and distribution of strain throughout the material so the deformation takes place over a larger volume (Ognedal 2012). The volumetric strain energy necessary to form a void around a particle is derived from two sources: differential thermal contraction and mechanical loading, see (Ayre and Bucknall 1998)

According to Fig. 4, the stress whitening is more intense and homogeneously distributed for higher grade number, viz. RT-PMMA100, or equivalently less intense and homogeneously distributed for lower grade number, viz. RT-PMMA45. This propensity of RTPMMA100 to micro-voiding induced stress whitening explains its better ductility and resulting Charpy impact toughness.

\section{Experimental procedure}

The specimens, impact test experimental set-up and instrumentation devices are presented in this section.
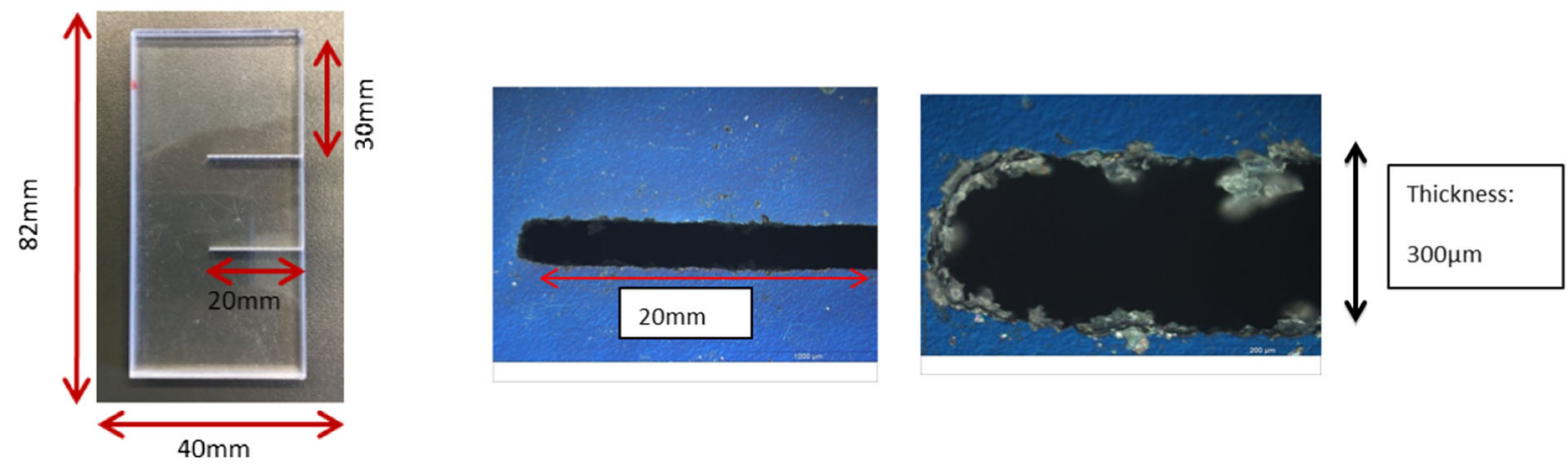

Fig. 5 KW specimens for impact test. Left: Coarse view. Right: Fine view of the notch

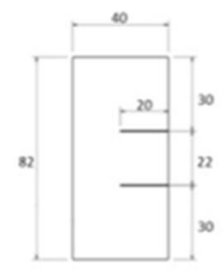

(a)

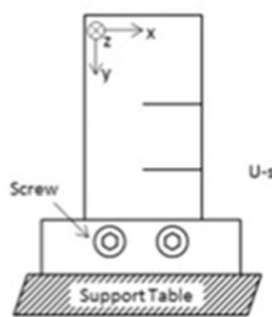

(c)

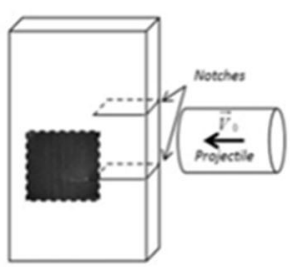

(b)

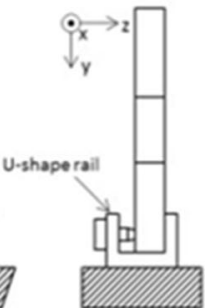

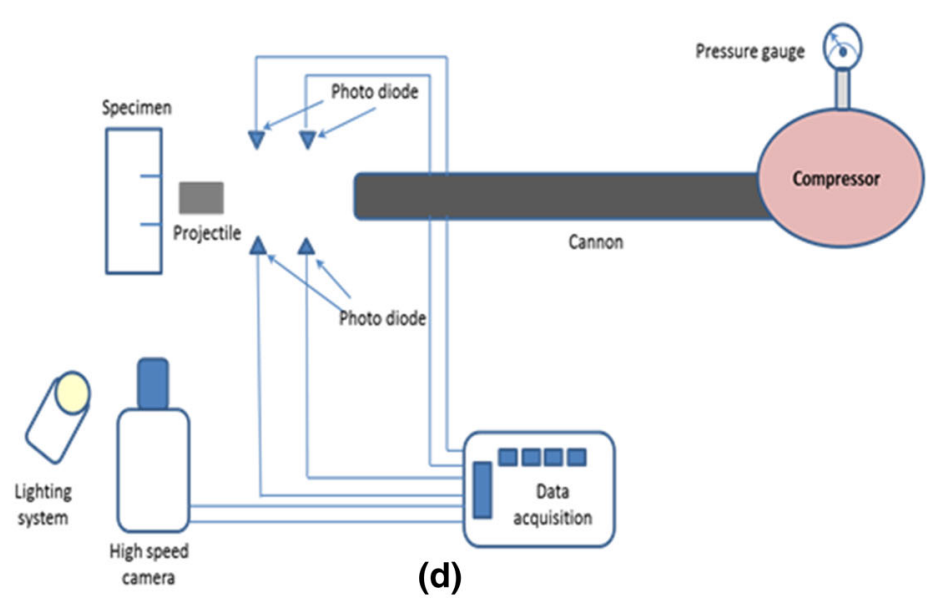

(d)

Fig. 6 Schematic view of the impact tests. a Specimen dimensions. b Projectile-specimen interaction. c Plate on its holder (Roux et al. 2015), d data acquisition system 


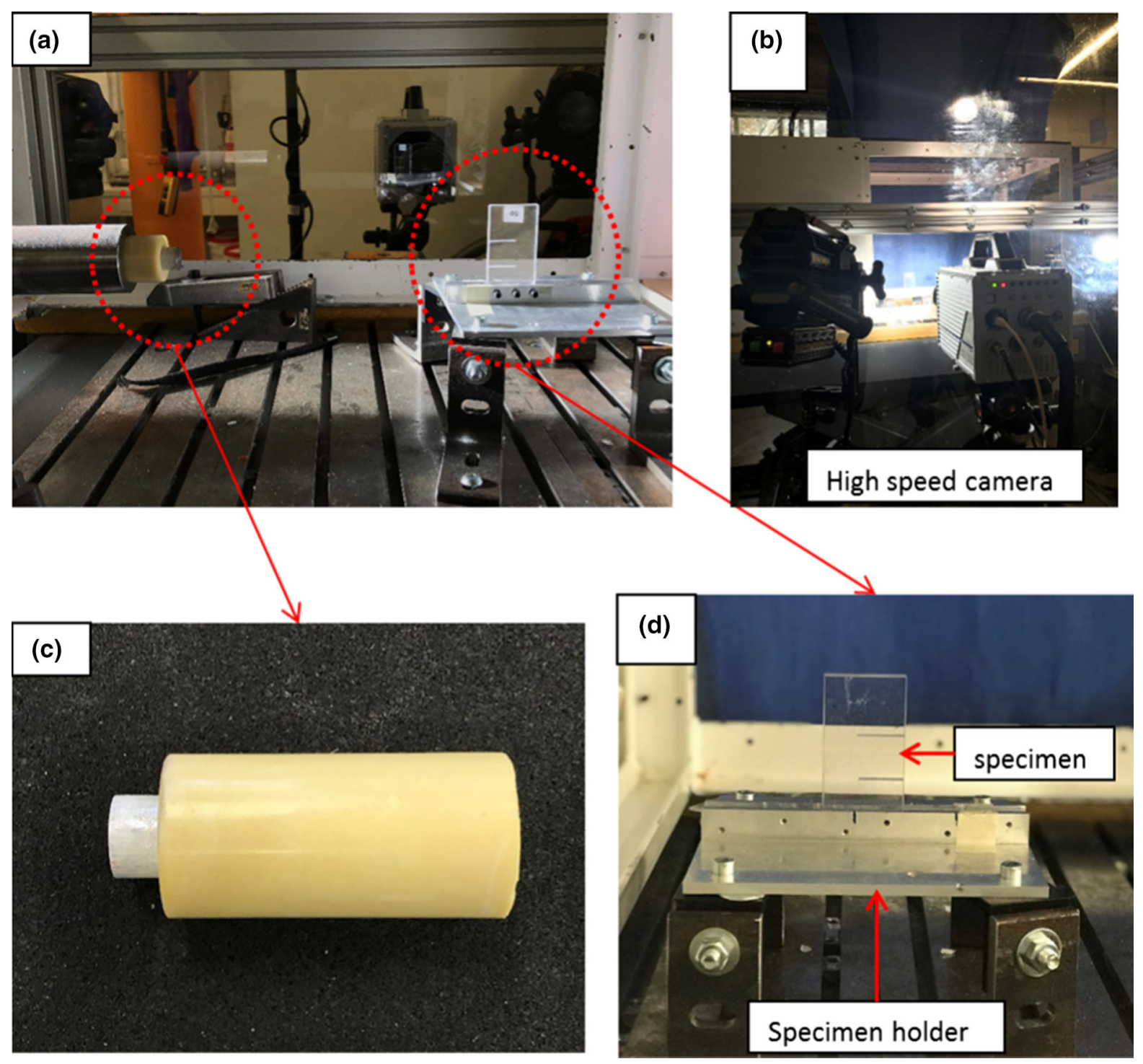

Fig. 7 Specimen in a closed chamber. b High speed camera, $\mathbf{c}$ steel projectile inside a polystyrene foam, $\mathbf{d}$ specimen placed on top of a holder

\subsection{Specimens}

As mentioned in the Introduction, KW-type impact tests consist of impacting the edge of a double notched plate made of the material at stake. As shown in Fig. 5 , the plate has two parallel notches which reproduce the pre-cracks of the real structure. The dimensions for KW-type specimens used in the present work are $40 \times 82 \times 6 \mathrm{~mm}^{3}$. The $20 \mathrm{~mm}$-length and $300 \mu \mathrm{m}-$ thickness notches were prepared by using a wire saw cutter. The detailed view of the notch in Fig. 5 shows that the notch tip is blunt. Wire cutting induced residual stresses are known to play a role in crack initiation. Yet, confined at the vicinity of the notch lips, they are expected to vanish far from the notch lips.

\subsection{Experimental set up}

Institut Clément Ader's STIMPACT impact platform consists of three $6 \mathrm{~m}$-length gas launchers with inner diameters of 40, 60 and $120 \mathrm{~mm}$ and a closed cham- 
ber where to place the test specimens. In the present work, the $40 \mathrm{~mm}$-inner diameter gas launcher was used. A gas pressure ranging typically between 0.5 and 10 bar allows for launching a $100 \mathrm{~g}$-weight projectile at a speed ranging typically between 20 and $350 \mathrm{~m} / \mathrm{s}$. Various impact velocities were used in this study ranging between 20 and $100 \mathrm{~m} / \mathrm{s}$.

Figure 6 shows the schematic view of the impact test experimental set-up and Fig. 7 some details. The specimen is loosely tightened on a specimen holder and then placed inside the closed chamber, see Fig. $7 \mathrm{~d}$. The projectile consists of a sub-calibrated, $25 \mathrm{~mm}$ length and $20 \mathrm{~mm}$-diameter steel projectile inserted in a $80 \mathrm{~mm}$ length and $40 \mathrm{~mm}$-diameter polystyrene foam guide, see Fig. 7c.The diameter of the steel projectile is slightly lower than the distance between the two notches.

Before each test, a laser alignment method is used to position accurately the KW-type specimen with respect to the gas tube axis and further projectile trajectory. The projectile speed is measured by means of 2 pairs of photodiodes, 2 emitters and 2 receivers, see Fig. $6 \mathrm{~d}$. The signals of the photodiodes are used to trigger the high-speed camera.

The experimental set up also includes a high speed camera in order to capture pictures of the speci$\mathrm{men} /$ projectile interaction and specimen failure. The Photron SA5 high speed camera resolution was synchronized with the system at $10^{5}$ fps (frame per second), that means a frame every $10 \mu \mathrm{s}$, and $320 \times$ 192 pixel $^{2}$ spatial resolution. Fragments produced during the tests were collected for further investigation.

\subsection{Microscopic examination}

Fractured surfaces from collected fragments were examined by Scanning Electron Microscope (Philips XL30ESEM). In order to provide an electrically conductive surface layer, the surface was coated with gold using Polaron FC500 from Fison Instrument. A voltage of $10 \mathrm{kV}$ was used due to the sensitivity of PMMA to the electron beam. Specimens were put inside a sputtering machine for 5-10 mins for optimum coating surface. The specimens are coated with gold and then viewed directly under the microscope.

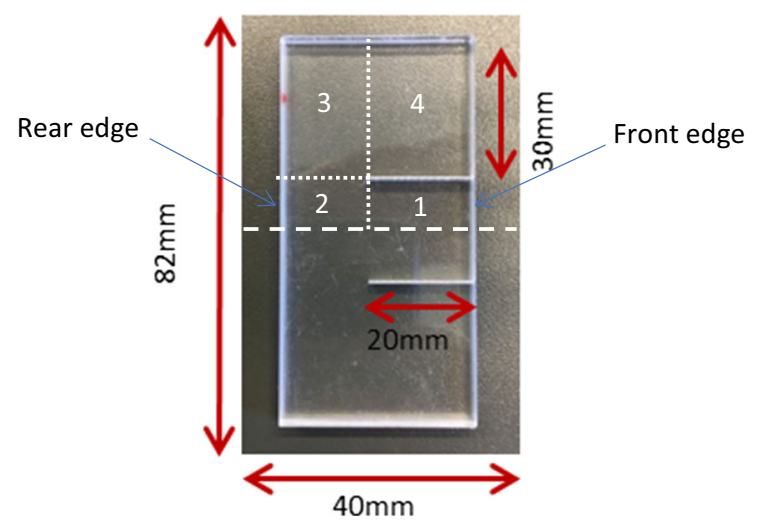

Fig. 8 Designation of the different parts of the KW-type specimen upper half. Part 1: Impacted part; Part 2: Left Center part \& Rear edge; Part 3: Left Upper part; Part 4: Right Upper part

\section{Results and analysis}

In this section, we investigate the mechanisms of failure of the impacted shock-resistant RT-PMMA specimens. The interaction between the plate and the projectile is discussed in depth. The kinematics of the crack propagation near and above the critical impact velocity at crack arrest is in particular analyzed and crack tip velocities are evaluated. In the following, the specimen parts are defined according to Fig. 8 and the comments will be done on the upper parts only, for symmetry reason. In order to check the repetitiveness of the results, each test was carried out at least twice for each configuration.

\subsection{Crack arrest}

We are here searching for the critical impact velocity value below which the crack, initiated from the notch tip, is arrested inside the specimen and above which the crack has propagated throughout the whole specimen leading to catastrophic failure. For that purpose, impact tests were carried out at $20 \mathrm{~m} / \mathrm{s}, 25 \mathrm{~m} / \mathrm{s}, 30 \mathrm{~m} / \mathrm{s}$ and 40 $\mathrm{m} / \mathrm{s}$.

\subsubsection{Post-mortem specimens near the critical impact velocity}

The pictures of the post-mortem specimens are shown in Fig. 9 where specimens are placed according to increasing impact velocity from left to right for each 
Fig. 9 KW specimens after impact test at 20,25, 30 and $40 \mathrm{~m} / \mathrm{s}$ from left to right of a RT-PMMA45, b

RT-PMMA65, and c RT-PMMA100. Only different post-mortem specimens are shown (a)

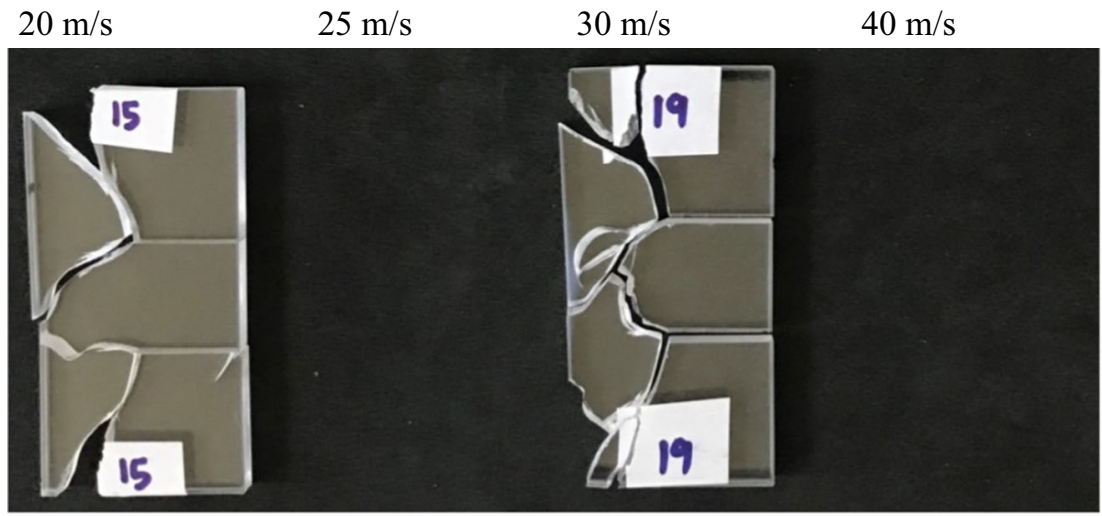

(b)

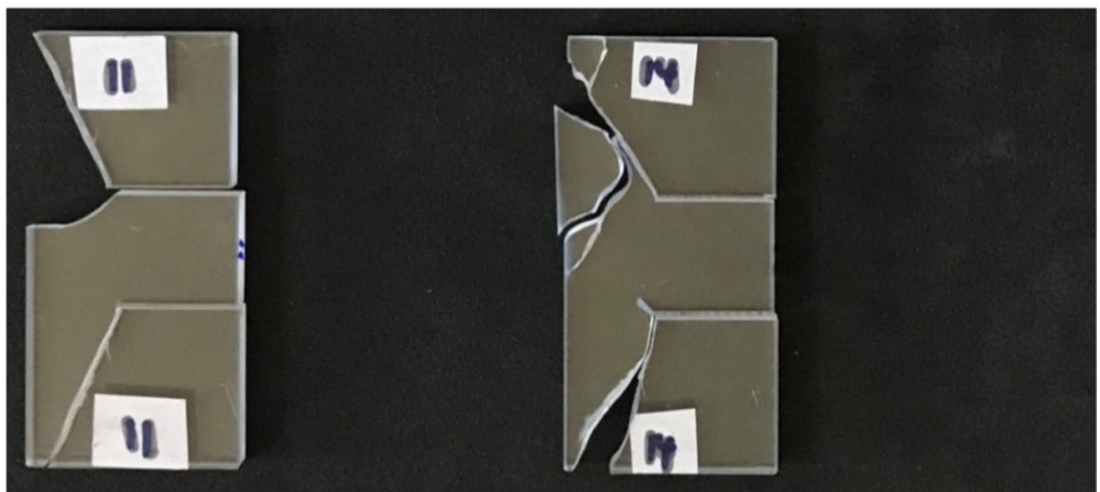

(c)

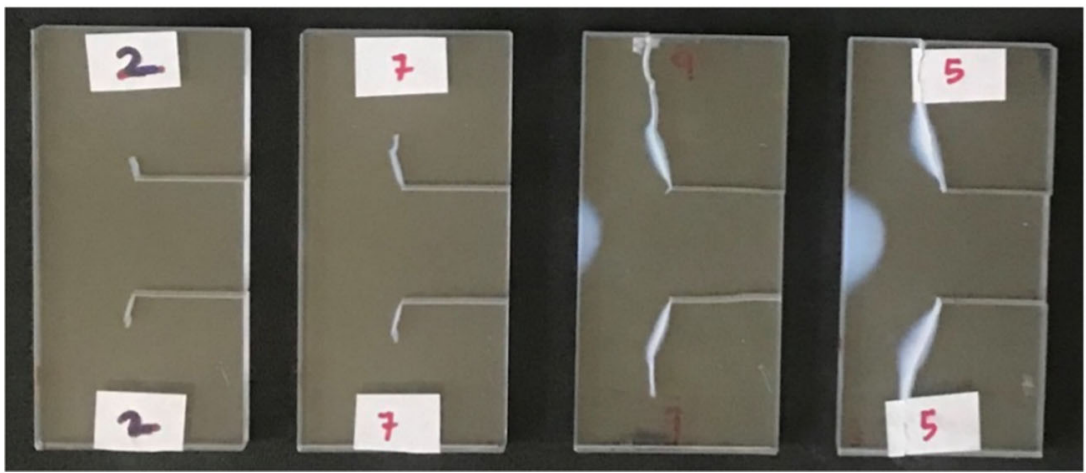

grade. According to Fig. 9, the critical impact velocity for crack arrest is close to $30 \mathrm{~m} / \mathrm{s}$ for RT-PMMA100. On the other hand, specimens made of RT-PMMA65 and RT-PMMA45 fail at the lowest impact velocity reachable using the gas launcher, viz. $20 \mathrm{~m} / \mathrm{s}$. Figure 9 also shows that whatever the grade the failure results in a low number fragments. For RT-PMMA100, the failure results from the propagation from the notch tip of a single crack inside Part 3 with an angle close to $70^{\circ}$ with respect to the notch orientation, whereas for the other grades and RT-PMM45 in particular it seems to results from the combination of two cracks initiated from the notch tip, one propagating with an angle close to $70^{\circ}$ inside Part 3 and the other one propagating with an angle close to $-45^{\circ}$ inside Part 2 .

\subsubsection{Kinematic analysis of the crack propagation near the critical impact velocity}

Frames recorded using the high-speed camera for the 30 $\mathrm{m} / \mathrm{s}$-impact velocity configuration on KW specimens made of RT-PMMA45 are shown in Fig. 10. These frames show that the crack propagating with an angle close to $-45^{\circ}$ inside Part2 initiates far after the one 

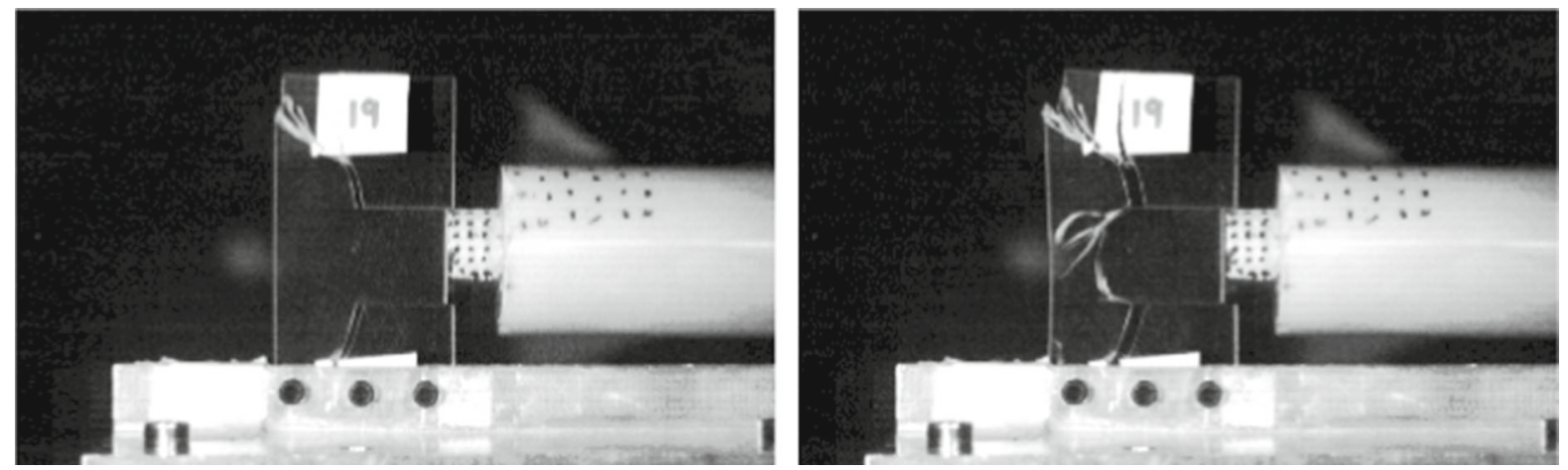

Fig. 10 Sequences of frames recorded by the high-speed camera at impact velocity of $30 \mathrm{~m} / \mathrm{s}$. RT-PMM45. $50 \mu \mathrm{s}$ between the two frames

propagating with an angle close to $70^{\circ}$ inside Part 3 . The latter is thus responsible for the main/catastrophic failure while the former leads to further fragmentation.

\subsection{Dynamic fracture}

Here, we are interested in the dynamic fracture mechanisms leading to multi-fragmentation, i.e. for impact velocities greater than the critical impact velocity at crack arrest. For that purpose, impact tests were carried out at $50 \mathrm{~m} / \mathrm{s}, 80 \mathrm{~m} / \mathrm{s}$ and $100 \mathrm{~m} / \mathrm{s}$.

\subsubsection{Post-mortem specimens above the critical impact velocity}

The fragments of specimens collected after the impact test are shown in Fig. 11a-c where fragments are placed according to increasing impact velocity from left to right for each grade. According to Fig. 11a, RT-PMMA45 failure results in many fragments which make their collection after impact difficult. Almost similar observations can be made for RT-PMMA65, see Fig. 11b. On the other hand, only a few, large fragments were produced for RT-PMMA100, see Fig. 11c. Tension loading-induced white regions are visible on fragments, mostly near the rear (left) edge of the post-mortem specimens inside Part 2, for the three grades and for the three impact velocities, over a cumulated stretch greater for RT-PMMA100 and high impact velocity (resp. lower for RT-PMMA45 and low impact velocity).

According to Fig. 11, one can conclude that
- whatever the grade number, the higher the impact velocity the larger the number of fragments and the greater the cumulated whitened regions,

- whatever the impact velocity, the lower the grade number, i.e. the lower the rubber concentration and resulting impact toughness, the larger the number of fragments and the smaller the cumulated whitened regions.

Rubber nanoparticles constitute soft obstacles to crack propagation and prevent crack branching. This mechanism is expected to slow down the crack propagation, i.e. reduce the crack propagation velocity, as shown later in Sect. 4.3. As a consequence, the fracture of a structure made of RT-PMMA with a high concentration in rubber nanoparticles (RT-PMMA100) results in a low number of fragments whereas the fracture of a structure made of RT-PMMA with a poor concentration in rubber nanoparticles (RT-PMMA45) results in a large number of fragments.

\subsubsection{Kinematic analysis of the crack propagation above the critical impact velocity}

Examples of frames recorded using the high-speed camera for the $80 \mathrm{~m} / \mathrm{s}$-impact velocity configuration considering the three grades are shown in Fig. 12. The sequence of frames allows for visualizing the successive steps of the RT-PMMA grades failure. It must be noted that the time $t=0$ is the time at which the projectile cuts the photodiode beam and triggers the highspeed camera recording and not the time at which the projectile hits the plate edge. Time $t=30 \mu$ s is the time just after the projectile has hit the plate (right) edge, and times $\mathrm{t}=50 \mu \mathrm{s}$ and $\mathrm{t}=70 \mu \mathrm{s}$ are other arbitrary times 
Fig. 11 KW specimens after impact test at 50, 80 and $100 \mathrm{~m} / \mathrm{s}$ of $\mathbf{a}$ RT-PMMA45, b RT-PMMA65, and c RT-PMMA100
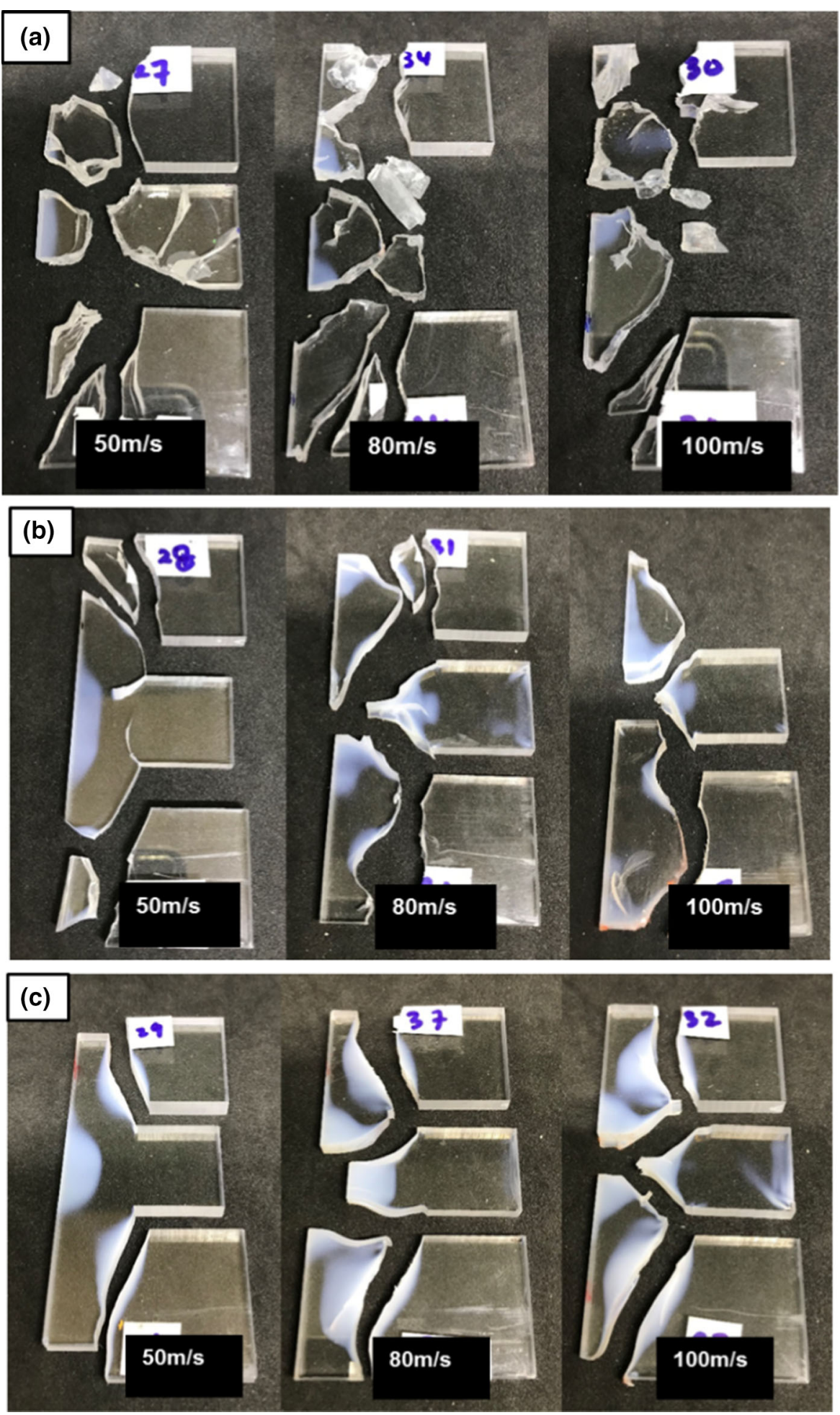


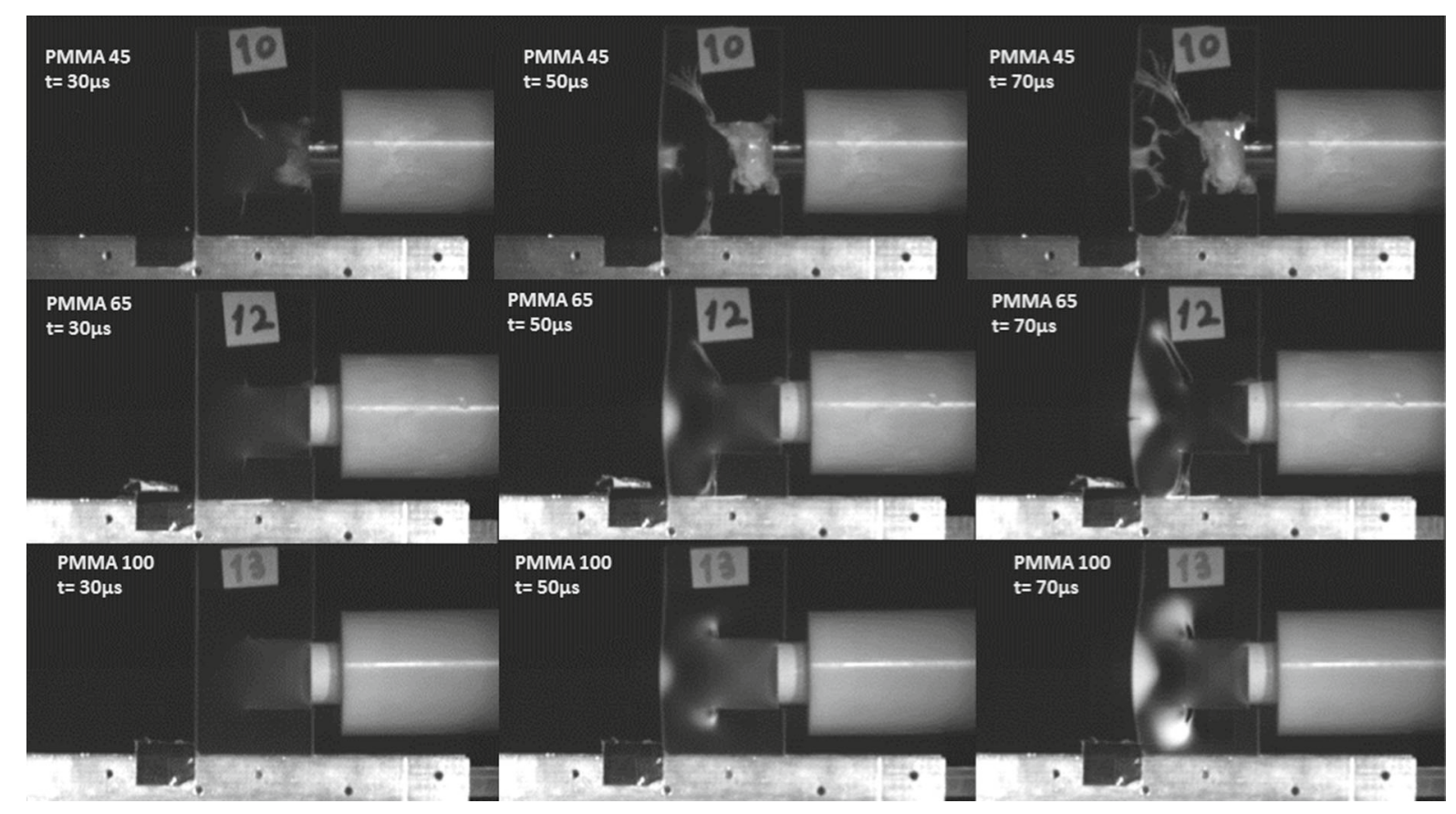

Fig. 12 Sequences of frames recorded by the high-speed camera at impact velocity of $80 \mathrm{~m} / \mathrm{s}$. Up: RT-PMM45. Intermediate: RTPMMA65. Bottom: RT-PMMA100

when interesting failure-related phenomena are visible on frames. Whatever the grade and the impact velocity, Part 4 undergoes no damage. In the following, we describe the mechanisms of dynamic fracture in Parts 1-3 for each grade.

- At time $\mathrm{t}=30 \mu \mathrm{s}$, see Fig. 12 left

For RT-PMMA100 and RT-PMMA65, one can observe in Part 1 a slight stress whitening homogeneously distributed over the whole volume; whereas for RT-PMMA45, the fragmentation has already begun. For the three grades one can observe in Part 2 a fading of the stress whitening present in Part 1. In Part 3, for RT-PMMA100, one can see the crack initiation at the notch tip; for RT-PMMA65, the start of Mode I crack propagation along a direction (quasi) perpendicular to the notch axis; and for RT-PMMA45, a significant Mode I crack propagation along a direction with an angle close to $70^{\circ}$ wrt notch axis-note the bifurcation of the crack which initially propagates (quasi) perpendicularly to the notch axis.

Even though it is submitted to compressive stress wave involving a predominant positive pressure state, the impacted part is subject to slight stress whitening which in principle appears under predominant positive
Table 3 Crack tip velocity average value $\dot{\bar{a}}$

\begin{tabular}{|c|c|c|c|}
\hline & $\begin{array}{l}\text { RT- } \\
\text { PMMA45 } \dot{\bar{a}} \\
(\mathrm{~m} / \mathrm{s})\end{array}$ & $\begin{array}{l}\text { RT- } \\
\text { PMMA65 } \dot{\bar{a}} \\
(\mathrm{~m} / \mathrm{s})\end{array}$ & $\begin{array}{l}\text { RT- } \\
\text { PMMA100 } \\
\dot{\bar{a}}(\mathrm{~m} / \mathrm{s})\end{array}$ \\
\hline $\begin{array}{l}\text { Impact at } 50 \\
\mathrm{~m} / \mathrm{s}\end{array}$ & 746 & 440 & 320 \\
\hline $\begin{array}{l}\text { Impact at } 80 \\
\mathrm{~m} / \mathrm{s}\end{array}$ & 643 & 383 & 370 \\
\hline $\begin{array}{l}\text { Impact at } 100 \\
\mathrm{~m} / \mathrm{s}\end{array}$ & 690 & 480 & 379 \\
\hline Average value & 693 & 434 & 356 \\
\hline
\end{tabular}

Table 4 Crack tip velocity average value/Rayleigh wave celerity ratio $\dot{\bar{a}} / C_{R}$

\begin{tabular}{llll}
\hline & RT-PMMA45 & RT-PMMA65 & RT-PMMA100 \\
\hline$\rho\left(\mathrm{kg} / \mathrm{m}^{3}\right)$ & 1180 & 1170 & 1160 \\
$C_{R}(\mathrm{~m} / \mathrm{s})$ & 861 & 765 & 627 \\
$\dot{\bar{a}} / C_{R}$ & 0.80 & 0.57 & 0.57 \\
\hline
\end{tabular}

hydrostatic stress state. On the other hand, the brittleness of RT-PMMA45 does not allow it to bear the compressive stress generated by the impact and the PMMA 


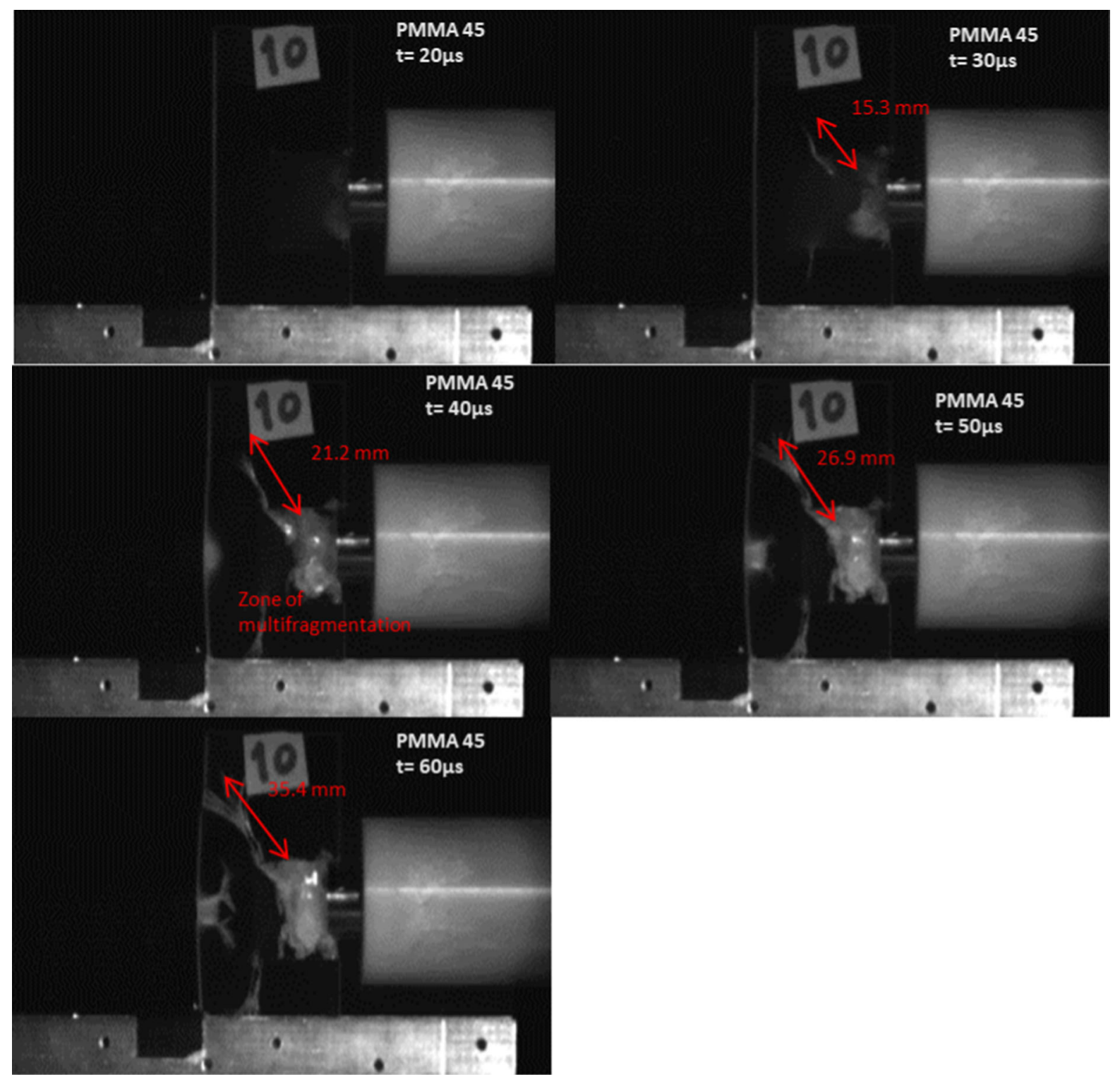

Fig. 13 Frame sequence for RT-PMMA45 at impact velocity $80 \mathrm{~m} / \mathrm{s}$

matrix fragments quasi instantaneously near the impact (front) edge. The start of crack propagation along a direction quasi perpendicular to or with an angle close to 70 wrt the notch axis evidences the brittle feature of the failure.

- At time $\mathrm{t}=50 \mu \mathrm{s}$, see Fig. 12 middle

In Part 1, for RT-PMMA100 and RT-PMMA65, a slight stress whitening is homogeneously distributed over the whole volume and a cross-shape localization bands pattern is forming, more pronounced for RT-
PMMA65; for RT-PMMA45, an intensification of fragmentation in the part near the projectile is clearly visible, while the slight stress whitening in the part far from the projectile has vanished. For RT-PMMA100 and RT-PMMA65 in Part 2, the formation (more pronounced for RT-PMMA65) of a semi elliptic stress whitening region near the rear edge under bending can be seen; for RT-PMMA45, one can observe a concentrated stress whitening region near the rear edge wherefrom cracks initiate. In Part 3, for RT-PMMA100, the 


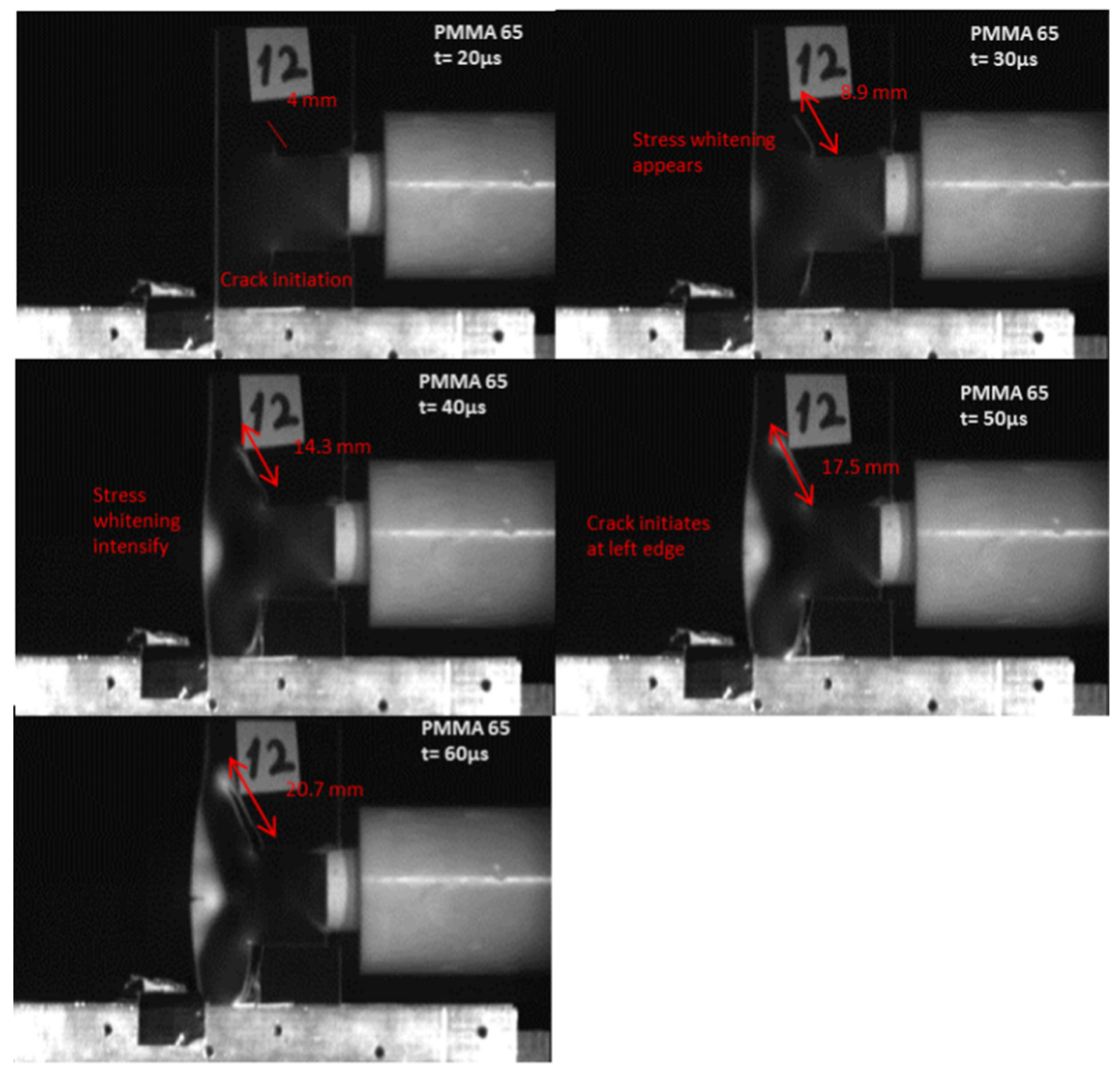

Fig. 14 Frame sequence for RT-PMMA65 at impact velocity $80 \mathrm{~m} / \mathrm{s}$

start of Mode I crack propagation along a direction perpendicular to the notch axis is seen, note that the crack process zone is embedded within a concentrated stress whitening region; for RT-PMMA65, one can observe a significant Mode I crack propagation along a direction with an angle close to $70^{\circ}$ wrt notch axis - note the bifurcation of the crack which initially propagates perpendicularly to the notch axis; and for RT-PMMA45, multi-branching of the initially single crack is visible.

By permitting extra extension, micro-voiding allows the rear edge to bend for the toughest grades, viz. RT-
PMMA65 and RT-PMMA100. Conversely, to accommodate the tension loading at the rear edge the brittle RT-PMMA45 develops cracks. Moreover, the complex pattern of cracks for RT-PMMA45 results in a progressive stress relaxation of the specimen and further stress whitening vanishing.

- At time $\mathrm{t}=70 \mu \mathrm{s}$, see Fig. 12 right

In Part 1, for RT-PMMA100 and RT-PMMA65, one can see a progressive vanishing of the slight stress whitening, while the shear bands pattern partly 


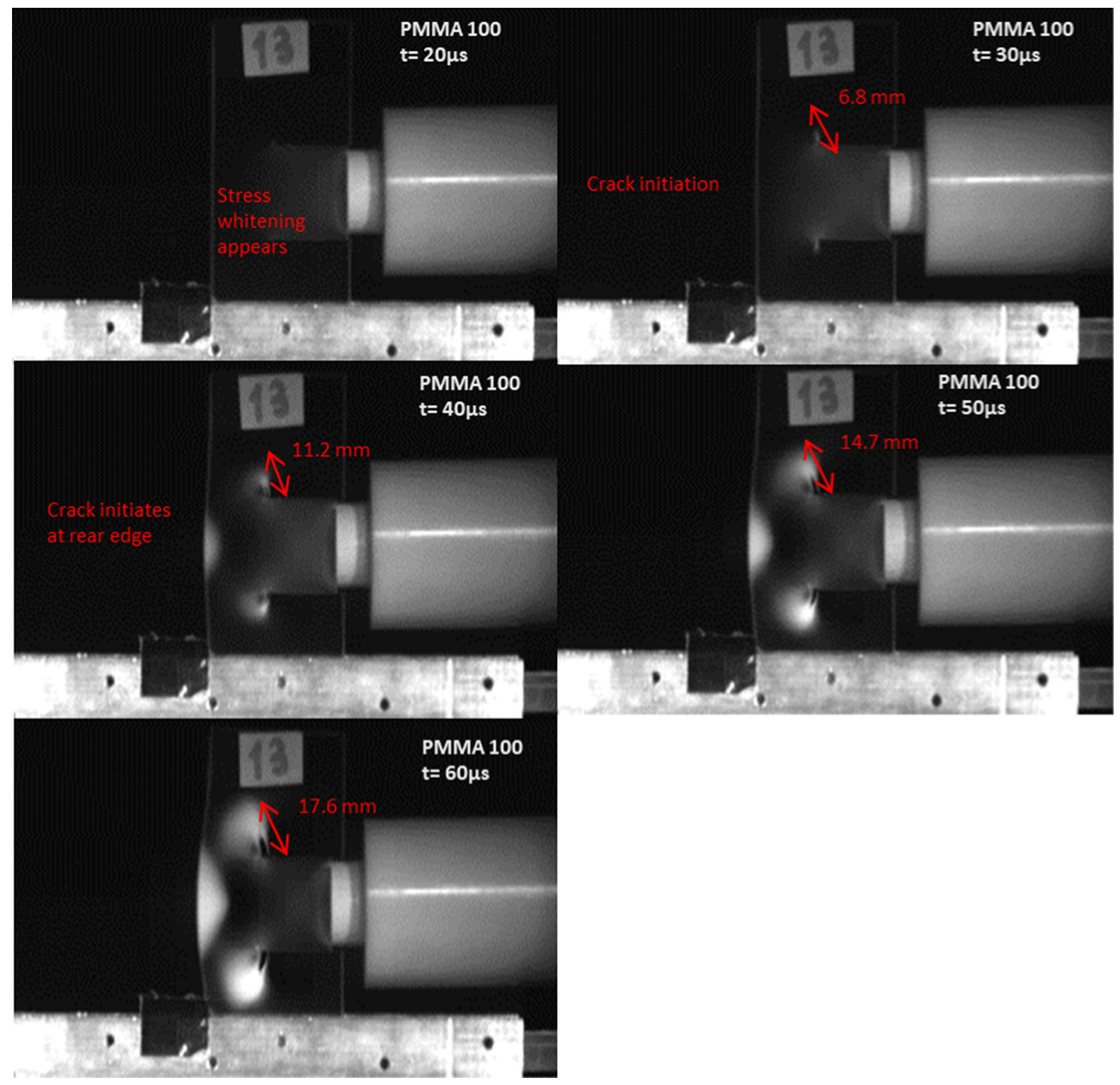

Fig. 15 Frame sequence for RT-PMMA100 at impact velocity $80 \mathrm{~m} / \mathrm{s}$

remains; in the same time RT-PMMA45 undergoes fragments compaction. In Part 2, for RT-PMMA100 and RT-PMMA65, one can observe an expansion (more pronounced for RT-PMMA65) of the stress whitening region, now in a triangle shape, near the rear edge under bending, and Mode I propagation and opening of a crack initiated from the rear edge for RT-PMMA65, note that for both grades the crack process zone is embedded within a wide stress whitening region; for RT-PMMA45, the multi-branching of the previous cracks is visible. In Part 3, for RT-PMMA100 and RTPMMA65, the slight Mode I propagation and significant opening of the crack is seen; in RT-PMMA45, one can observe the opening of the multi-branches.

The presence of wide regions of stress whitening at the crack tip/process zone for the toughest grades, viz. RT-PMMA65 and RT-PMMA100, demonstrates that micro-voiding plays its crack arrest role by dissipating energy and preventing crack propagation. It is noteworthy that this phenomenon may be reversible since the 

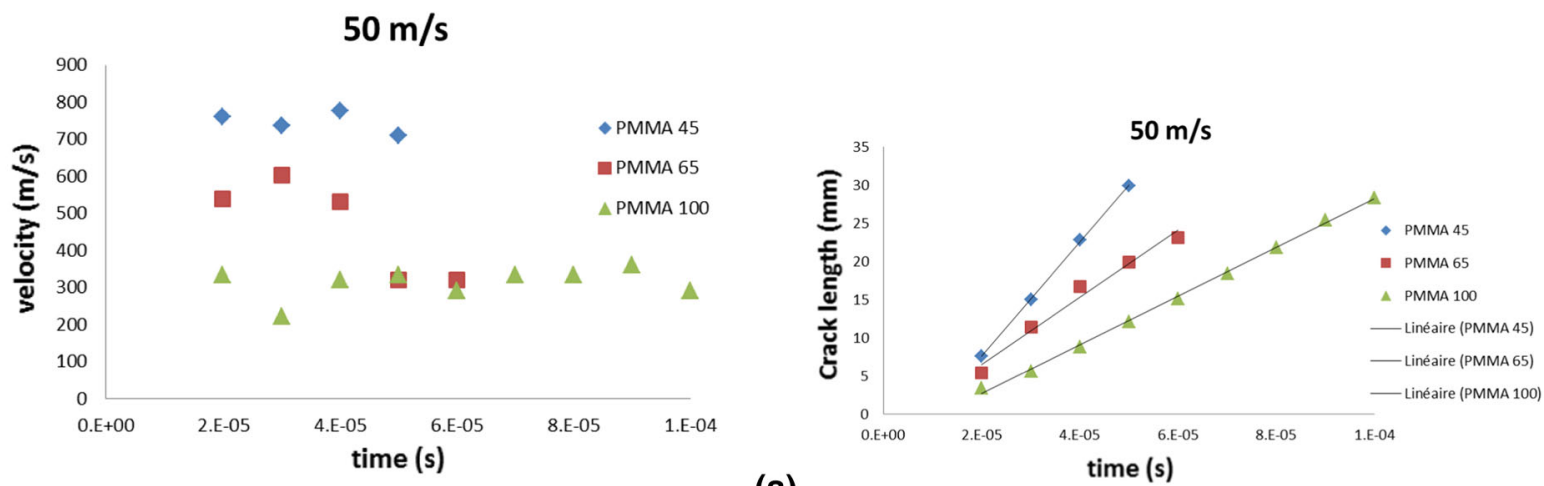

(a)

\section{$80 \mathrm{~m} / \mathrm{s}$}
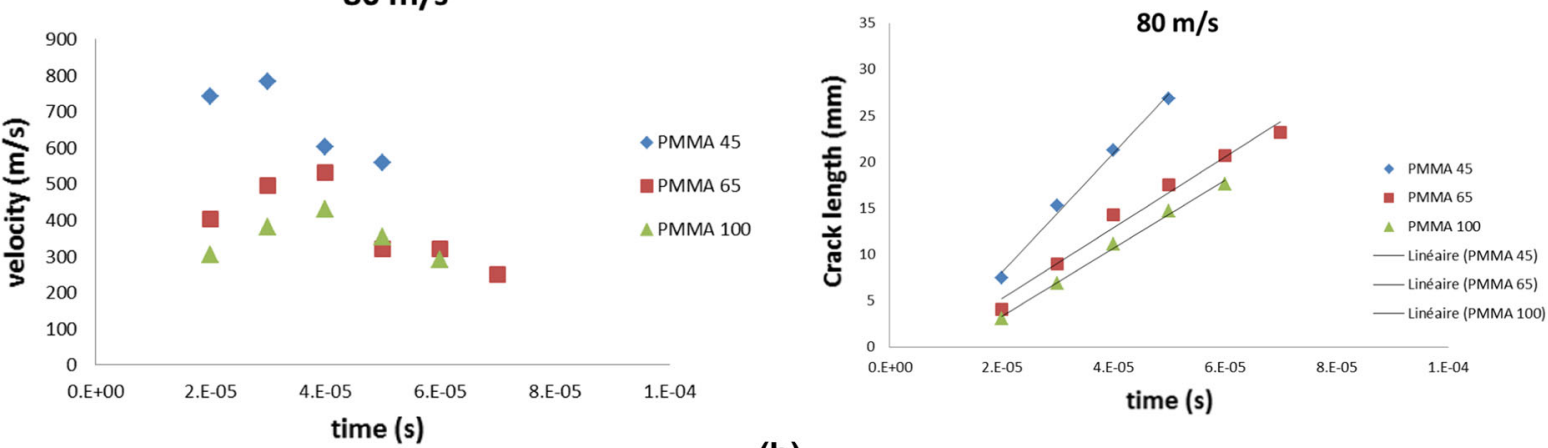

(b)
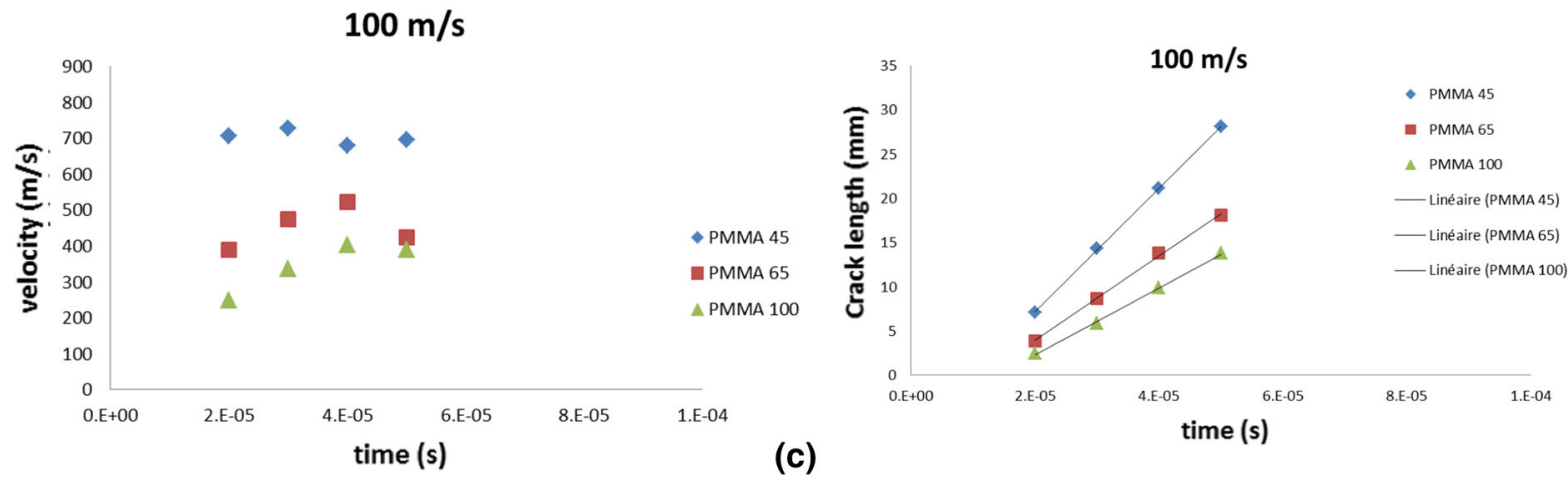

Fig. 16 Histories of current crack tip velocity $\dot{a}$ and crack length $a$ for the three RT-PMMA grades at impact velocity of a $50 \mathrm{~m} / \mathrm{s}, \mathbf{b}$ $80 \mathrm{~m} / \mathrm{s}$ and $\mathbf{c} 100 \mathrm{~m} / \mathrm{s}$

white regions can recover their transparency in certain situations.

\subsection{Crack tip velocity estimation}

Digital image analysis of the frames recorded using the high-speed camera can be conducted to describe the crack propagation process and further estimate the crack tip velocity. Frames used to that purpose are reported in Figs. 13, 14 and 15 for RT-PMMA45, RTPMMA65 and RT-PMMA100, respectively, for impact velocity of $80 \mathrm{~m} / \mathrm{s}$. In the following, we are interesting in the main cracks initiated from the notches tips. The histories of current crack tip velocity $\dot{a}$, i.e. computed between two successive frames, and current crack length $a$ for each grade are plotted in Fig. 16 for impact velocities of 50,80 and $100 \mathrm{~m} / \mathrm{s}$, with the principle of their estimation outlined in Figs. 13, 14 and 15. The 
Fig. 17 Fragments produced after impact test at $50 \mathrm{~m} / \mathrm{s}$. Left RT-PMMA45. Center RT-PMMA65. Right RT-PMMA100

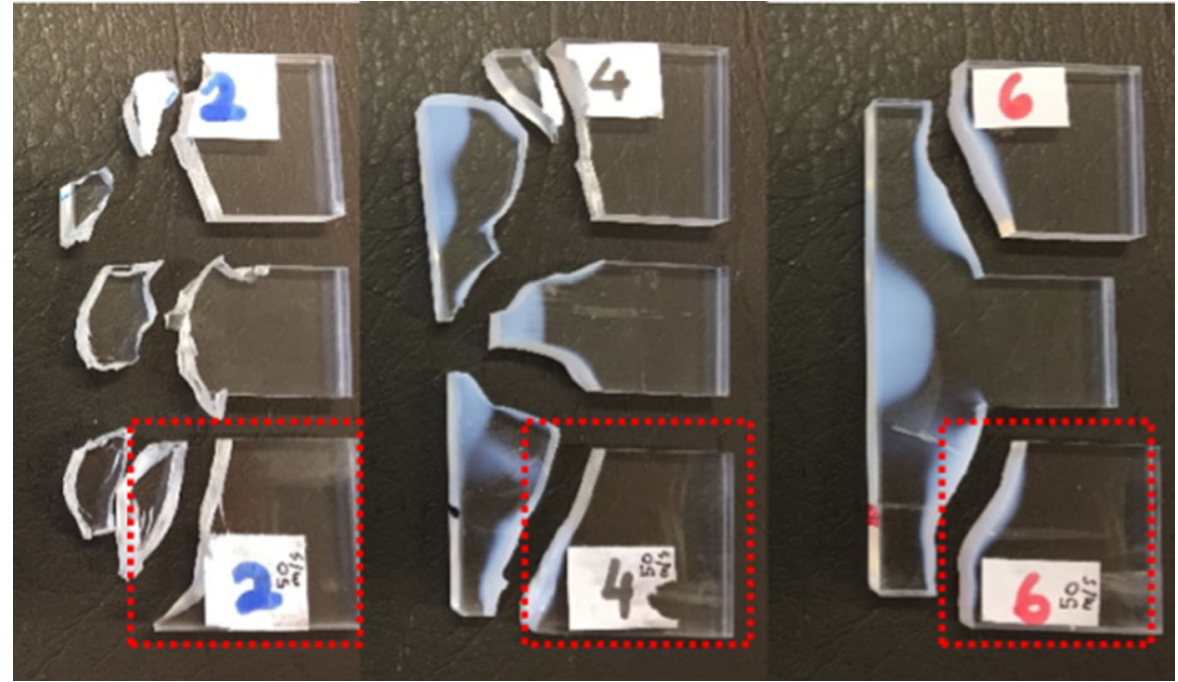

average values of crack tip velocity $\dot{\bar{a}}$ computed from a linear regression of the crack length wrt time, see Fig. 16 right, for each grade and each impact velocity are reported in Table 3. In Table 4 are reported the ratios of the average values (over the three impact velocities) of crack tip velocity $\dot{\bar{a}}$ over the Rayleigh wave speeds $C_{R}$ for the three grades. The $C_{R}$ is estimated according to

$\frac{C_{R}}{C_{S}}=\frac{0.862+1.14 v}{1+v} ; C_{S}=\sqrt{\frac{\mu}{\rho}} ; \mu=\frac{E}{2(1+v)}$

where $E, \mu, v$ represent the Young's modulus, shear modulus and Poisson's ratio, respectively, and where $C_{S}$ is the shear wave speed. All the coefficients depend on the grade, except $v$ which is taken as constant $(v=$ $0.33)$.

- Influence of the impact velocity

According to Table 3, the impact velocity has no significant effect on the average crack tip velocitymaybe a very slight decrease with an impact velocity increase.

- Influence of the grade

Figure 16 left and Table 3 show that whatever the impact velocity the lower the grade number the higher the crack tip velocity, or equivalently the higher the grade number the lower the crack tip velocity. Indeed, average (over the three impact velocities) crack tip velocity values are $693 \mathrm{~m} / \mathrm{s}$ for RT-PMMA45, $434 \mathrm{~m} / \mathrm{s}$ for RT-PMMA65 and $356 \mathrm{~m} / \mathrm{s}$ for RT-PMMA100, that means a value for RT-PMMA45 which is two times greater than the one for RT-PMMA100. According to Table 4, for RT-PMMA65 and RT-PMMA100 the dimensionless average crack tip velocity is the same and does not exceed 0.57 , while the instantaneous crack tip velocity could be higher while remaining lower than the Rayleigh wave speed. The value of $0.80 C_{R}$ for RT-PMMA45 average crack tip velocity is higher and approaches Rayleigh wave speed. The ratio $\dot{\bar{a}} / C_{R}$ may be associated with the loss of toughness under dynamic loading when compared to static loading. As a consequence, the loss of toughness due to dynamic loading is more important for RT-PMMA45, see also Table 1, explaining its premature failure under impact loading when compared to the two other grades.

These results show that cracks propagate more easily inside RT-PMMA45, resp. less easily inside RTPMMA100, due to the lower impact toughness and resulting crack arrest capability, resp. higher impact toughness and resulting crack arrest capability, of the composite material. As the grade increases, the higher rubber volume fraction aids to toughen the material and resist the crack propagation.

\subsection{Fracture analysis}

Fracture surfaces of the RT-PMMA under consideration were observed using SEM in view of determining the failure micro-mechanisms. The SEM investigation has been conducted on the specimen parts shown in Fig. 17 and on the crack planes A and B shown in the left part of Fig. 18, which indicate the planes of the main cracks initiated from the notches tips. Zone A starts 


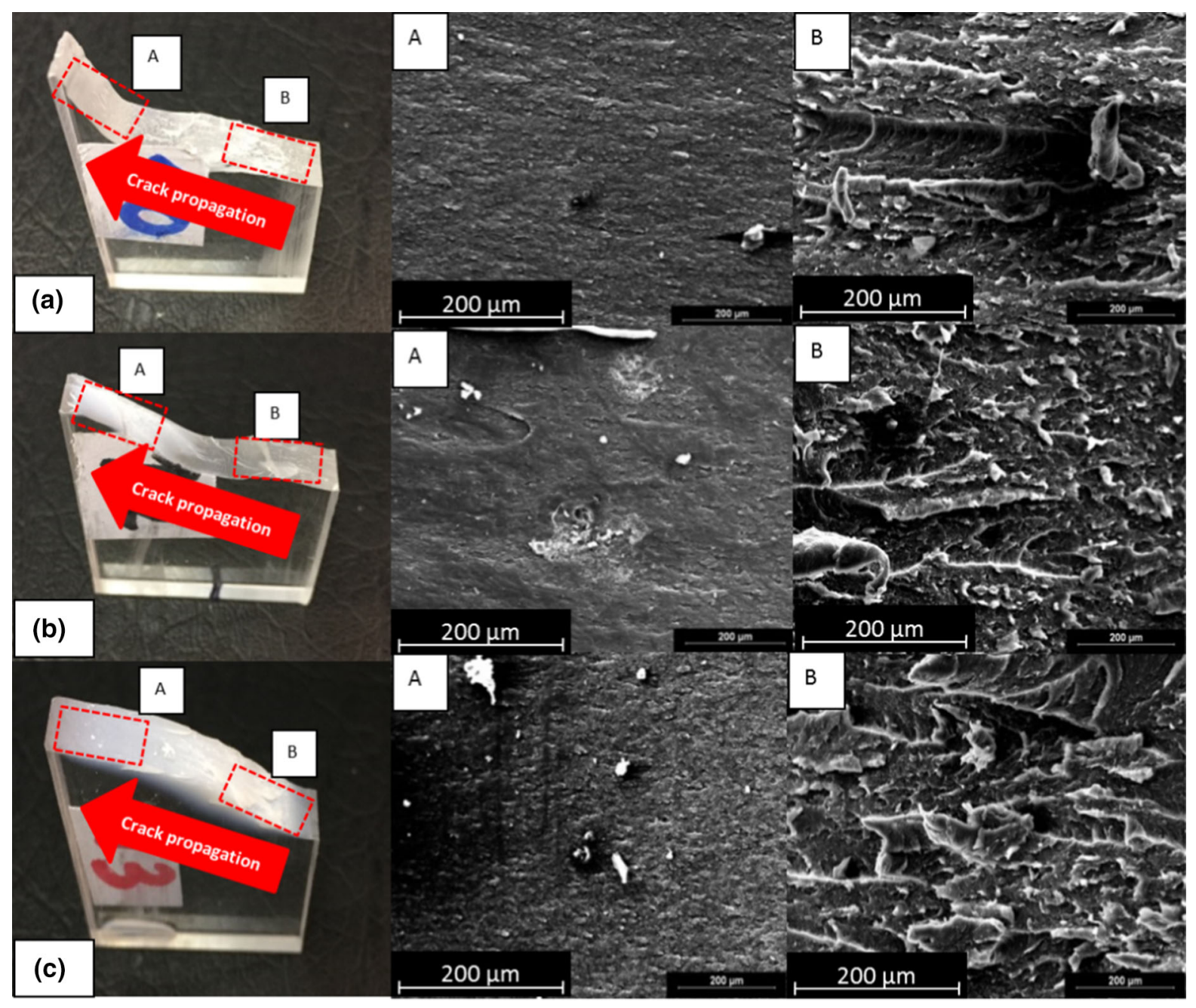

Fig. 18 Fracture surfaces for a RT-PMMA45, b RT-PMMA65, c RT-PMMA100, after impact test at $50 \mathrm{~m} / \mathrm{s}$

at the notch tip and corresponds to the early stage of crack propagation while zone $\mathrm{B}$ ends at the rear edge and corresponds to the late stage of crack propagation leading ultimately to full fracture of the specimen.

Pictures on the left of Fig. 18 show clearly the bifurcation of the crack plane during its propagation. Detailed views of zones A and B in Fig. 18 center and right show that, whatever the grade and whatever the impact velocity (SEM pictures for impacts at $80 \mathrm{~m} / \mathrm{s}$ and $100 \mathrm{~m} / \mathrm{s}$ are not shown here), the fracture surface during early stage of crack propagation is rough whereas during late stage of crack propagation it is smooth. The roughness is higher for RT-PMMA100, see Fig. 18 right bottom, with a dimple cluster-like aspect.
Rough surfaces show that the material has undergone inelastic deformation, which implies that shear loading takes place (Porfyrakis et al. 2002). According to $\mathrm{Wu}$ et al. (2004), dispersion of rubber particles which acts to enhance toughness of PMMA matrix is also a reason for shear loading to occur. The induced shear yielding stress volume is around the rubber particle. The specimen is tough when these stress volumes form a vast interconnected network for a certain particle concentration. This network pervades throughout the specimen and hence makes it tough (Cheng and Chen 2004). Transition of rough to smooth region also evidences changes of velocity and crack arrest as seen in Brown et al. (2014), Shioya et al. (1988). Unfortunately, due to the absence of contrast between rubber 
nano-particles and PMMA matrix, it was not possible to report any clear pictures showing the presence of rubber particles incorporated inside the PMMA and nanoparticle/matrix debonding as source of stress whitening as reported in Plummer et al. (1999), Cho and Yang (1998), Gong and Bandyopadhyay (2007) Porfyrakis et al. (2002).

\section{Concluding remarks}

Crack arrest capability is a requirement for structures likely to undergo accidental overloads. In the present work, the crack arrest capability under impact loading of three commercial grades of RT-PMMA possessing different Charpy impact toughness values - the higher the grade number the higher the Charpy impact toughness value-, is experimentally investigated. Double notched plates made of the materials were accordingly submitted to impact-on-edge loading. Among the three grades of RT-PMMA, RT-PMMA100 demonstrates higher resistance to crack and less number of fragmentations produced after impact. This proves that addition of rubber to the PMMA matrix aids to enhance the poor toughness properties of plain PMMA. Specimens fail in less brittle manner as the grade number increases.

Estimation of crack tip velocity shows that crack propagates at higher velocity for RT-PMMA45 and lower velocity for RT-PMMA65 and RT-PMMA100. This proves that incorporating rubber nano-particles in a PMMA matrix helps slow down the crack propagation and favor crack arrest. Indeed, debonding and void growth act together to promote energy dissipation throughout the material. This process is visible in macroscopic scale through stress whitening.

One can thus conclude that increasing the rubber nano-particle concentration in RT-PMMA favors the crack arrest capability under impact loading by promoting inelastic deformation, reducing the crack propagation velocity, limiting crack multi-branching, and reducing the number of fragments.

These results are expected to be used for developing/discriminating numerical modelling approaches aiming at reproducing the failure of RT-PMMA under impact loading within an engineering design process.

Acknowledgements The authors would like to acknowledge the technical assistance of ICA technical team and Centre de
MicroCaractérisation Raimond Castaing UMS 3623 as well as some financial support provided by AIRBUS Helicopters.

\section{References}

Abdel-wahab AA, Ataya S, Silberschmidt VV (2017) Temperature-dependent mechanical behaviour of PMMA?: Experimental analysis and modelling. Polym Test 58:86-95

Arruda EM, Boyce MC, Jayachandran R (1995) Effects of strain rate, temperature and thermomechanical coupling on the finite strain deformation of glassy polymers. Mech Mater 19:193-212

Awaja F, Zhang S, Tripathi M, Nikiforov A, Pugno N (2016) Cracks, microcracks and fracture in polymer structures?: Formation, detection, autonomic repair. Prog Mater Sci 83:536-573

Ayre DS, Bucknall CB (1998) Particle cavitation in rubbertoughened PMMA: experimental testing of the energybalance criterion. J Polym 39:4785-4791

Brown HR, Schneider JA, Murphy TL (2014) Experimental studies of the deformation mechanisms of core-shell rubbermodified diglycidyl ether of bisphenol-A epoxy at cryogenic temperatures. J Compos Mater 48:1279-1296

Bucknall CB, Partridge IK, Ward MV (1984) Rubber toughening of plastics. J Mater Process Technol 19:2064-2072

Cheng SK, Chen CY (2004) Mechanical properties and strainrate effect of EVA/PMMA in situ polymerization blends. Eur Polym J 40:1239-1248

Chou SC, Robertson KD, Rainey JH (1973) The effect of strain rate and heat developed during deformation on the stressstrain curve of plastics. Exp Mech 13:422-432

Chung JS, Choi KR, Wu JP (2001) Effect of polybutyl acrylatepolymethyl methacrylate rubber particle texture on the toughening behavior of polymethyl methacrylate. Korea Polym J 9:122-128

Farrokh B, Khan AS (2010) European Journal of Mechanics A / Solids A strain rate dependent yield criterion for isotropic polymers?: Low to high rates of loading. Eur J Mech A Solids 29:274-282

Gilbert JL, Ney DS, Lautenschlager EP (1995) Self-reinforced composite polymethyl methacrylate: static and fatigue properties. Biomaterials 16:1043-1055

Gong S, Bandyopadhyay S (2007) Fracture properties and fracture surface morphologies in rubber-PMMA composites. J Mater Eng Perform 16:607-613

Hsieh AJ, Deschepper D, Moy P, Dehmer PG, Song JW (2004) The effects of PMMA on ballistic impact performance of hybrid hard/ductile all-plastic- and glass-plastic-based composites, ARL report

Hu W, Guo H, Chen Y, Xie R, Jing H, He P (2016) Experimental investigation and modeling of the rate-dependent deformation behavior of PMMA at different temperatures. Eur Polym J 85:313-323

Jancar J, Hoy RS, Jancarova E, Zidek J (2015) Effect of temperature, strain rate and particle size on the yield stresses and post-yield strain softening of PMMA and its composites. Polymer 63:196-207

Jerjen I, Revol V, Brunner AJ, Schuetz P, Kottler C, Kaufmann R, Luethi T, Nicoletti G, Urban C, Sennhauser U (2013) 
Detection of stress whitening in plastics with the help of X-ray dark field imaging. Polym Test 32:1094-1098

Kalthoff JF, Winkler S (1987) Failure mode transition at high rates of loading, In: Proc. Int. Conf. Impact Load. Dyn. Behav. Mater. Chiem CY, Kunze H-D, Meyer LW (eds), Bremen, pp 185-195

Kilwon C, JaeHo Y (1998) Chan Eon Park, The effect of rubber particle size on toughening behaviour of rubber-modified poly(methyl methacrylate) with different test methods. J Polym 39:3073-3081

Kobayashi AS (1979) Rapid crack propagation and arrest in polymers. Polym Eng Sci 19:131-135

Lalande L (2007) Structure et mécanismes de microdéformation de polyméthylméthacrylates renforcés au choc, Ph.D. Thesis, École polytechnique fédérale de Lausanne

Mbarek IA, Matadi Boumbimba R, Rusinek A, Voyiadjis GZ, Gerard P, Samadi-Dookic A (2018) The dynamic behavior of polymethyl methacrylate based nano-rubbers subjected to impact and perforation: experimental investigations. Mech Mater 122:9-25

Miwa M, Takeno A, Hara K, Watanabe A (1995) Volume fraction and temperature dependence of mechanical properties of silicone rubber particulate/epoxy blends. Composites 26:371377

Nasraoui M, Forquin P, Siad L, Rusinek A (2012) Influence of strain rate, temperature and adiabatic heating on the mechanical behaviour of poly-methyl-methacrylate?: Experimental and modelling analyses. Mater Des 37:500509

Ognedal AS (2012) Large-deformation behaviour of thermoplastics at various stress states, Ph.D. Thesis, Department of Structural Engineering, Norwegian University of Science and Technology

Patent No : EP0776931

Pearson RA, Yee AF (1991) Influence of particle size and particle size distribution on toughening mechanisms in rubbermodified epoxies. J Mater Sci 26:3828-3844

Plummer CJG, Béguelin P, Kausch HH (1999) Microdeformation in core-shell particle modified polymethylmethacrylates. Colloids Surfaces 153:551-566
Porfyrakis K, Assender HE, Robinson IM (2002) The interrelationship between processing conditions, microstructure and mechanical properties for injection moulded rubbertoughened polymethyl methacrylate RTPMMA samples. J Polym 43:4769-4781

Ravi-Chandar K, Lu J, Yang B, Zhu Z (2000) Failure mode transitions in polymers under high strain rate loading. Int $\mathrm{J}$ Fract 101:33-72

Roux E, Longère $\mathrm{P}$, Cherrier $\mathrm{O}$, Millot $\mathrm{T}$, Capdeville $\mathrm{D}$, Petit $\mathrm{J}$ (2015) Analysis of ASB assisted failure in a high strength steel under high loading rate. Mater Des 75:149-159

Shioya T, Koga Y, Fujimoto K, Ishida R (1988) Micromechanism of dynamic crack propagation in brittle materials. J Phys Colloq 49:253-260

Smirnov I, Sudenkov Y (2013) Crack propagation in PMMA plates under various loading conditions. In: The 13th international conference on fracture, June 16-21, Beijing, China, pp $1-10$

Todo M, Takahashi K, Ben Jar P, Beguelin P (1999) NIIElectronic Library Service. Jpn Soc Mech Eng Int J 42:585591

Wang Q, Lee D (1999) Predictive modelling for rubbertoughened polymers. Mech Mater 31:705-716

Wang X, Ming K, Xiao LIN, Ye Y, Mai CH, Wang LRF (2000) Rose, modelling mechanical properties of core-shell rubbermodified epoxies. Acta Mater 48:579-586

Wu H, Ma G, Xia Y (2004) Experimental study of tensile properties of PMMA at intermediate strain rate. Mater Lett 58:3681-3685

Publisher's Note Springer Nature remains neutral with regard to jurisdictional claims in published maps and institutional affiliations. 